\title{
Implementation of the Technology Revolution 4.0: Monitoring and Measurement of Temperature, Distribution Current at Transformers Using Internet of Things
}

\author{
Suprianto Bambang, Budi Santoso Agus, Rijanto Tri
}

\begin{abstract}
Distribution transformer is the heart of the distribution network. Distribution transformers are expected to work continuously to supply electricity to customers. The emergence of disturbance in the distribution transformer results in damage to the transformer and interruption of power distribution to the customer. One of the disturbances in the distribution transformer can be caused by a short circuit or overcurrent loading which results in an upward current from nominal as well as an increase in winding temperature or around the transformer. This study aims to design and build a prototype of a current and temperature parameter monitoring system on an IoT-based transformer to improve efficiency, lifetime and to know the transformer's condition in real-time. The results of this study indicate that the prototype when compared to amperes pliers can respond to 3 phase current values that are read with an average measurement error or error accuracy per phase current $R=1.0 \%, S=1.8 \%, T=1$, $7 \%$, and the average measurement error or temperature error accuracy per phase $\mathrm{R}=3.1 \%, \mathrm{~S}=5.8 \%, \mathrm{~T}=\mathbf{8 . 0 \%}$.
\end{abstract}

Index Terms - Distribution Transformer, Current Sensor, Themperature Sensor.Monitoring (IoT), Blynk.

\section{INTRODUCTION}

One of the ways to improve the reliability of the electric power system is to maintain the continuity of the distribution of electrical energy. The distribution of electrical energy by raising or lowering the voltage must go through a power transformer. Transformer is electrical equipment that is very important which directly related to the electricity transmission and distribution line.

Interference with the transformer can cause damage and decrease the performance of the transformer. Examples of causes of transformer damage are overload and unbalanced loads. Overload occurs because the load attached to the transformer exceeds the maximum capacity of the transformer where the load current exceeds the full load current of the transformer. The transformer can also overload even though the load current has not exceeded the full load current because the transformer temperature has exceeded the allowable limit. $[1,8,9]$.

Suprianto, Bambang is a lecturer in UniversitasNegeri Surabaya (State Santoso, Agus Budi is a lecturer in UniversitasNegeri Surabaya (State University of Surabaya). Majoring in electrical Engineering with electronic education specialists.

Rijanto, Tri is a lecturer in UniversitasNegeri Surabaya (State University of Surabaya). Majoring inelectrical Engineering with electrical education specialists
To improve the services of PT. PLN to electricity consumers, they need to be maintained continuity from time to time. The distribution of electrical energy to consumers from a $20 \mathrm{kV}$ network always passes through a power transformer to convert a voltage to 220 VAC that can be utilized by consumers. Common constraints that occur, the power transformer that is in a voltage condition cannot be detected in real-time whether the transformer has a disturbance. So far, PT. PLN only conducts routine maintenance according to a schedule with a certain time and it is very difficult to know the condition of the transformer that experiences abnormal conditions if there is a disturbance outside the maintenance schedule. [2].

Based on the background of the problem this study aims to design and make a current prototype tool and temperature monitoring at the distribution transformer based on Internet of things (IoT) which expects to track and monitor the condition of the transformer in real-time.

\section{LITERATURE REVIEW}

\section{A. Distribution Transformer Network}

Distribution transformers convert primary voltage to low voltage that can be used by consumers. In Indonesia, transformers that used in distribution networks are three-phase transformers that have $(20 \mathrm{kV}-400 \mathrm{~V})$, whereas for single-phase transformers $(11.6 / 20 \mathrm{kV}-231 \mathrm{~V})$.

At the transformer's working point, the air temperature should not exceed $40{ }^{\circ} \mathrm{C}$ or with a daily average temperature power transformer when reviewed from high voltage (primary) side can be formulated as the following [10]:

$S=\sqrt{3 . V . I}$

So to calculate the full load current (full loaded) can be calculated [10]:

$$
\mathrm{I}_{\mathrm{FL}}=\frac{\mathrm{s}}{\sqrt{\mathrm{a}} \cdot \mathrm{v}}
$$

Where:

I_F $F_{L}=$ Full load current $(A)$

$\mathrm{S} \quad=$ Power Transformer $(\mathrm{kVA})$

$\mathrm{V} \quad=$ Secondary side voltage transformer $(\mathrm{kV})$

B. Internet Of Things (IoT)

The Internet of Things (IoT) refers to "a global network of physical objects and everyday goods that are capable of generating, exchanging and processing data with human 
mediation". The best definition for the Internet of Things is: An open and comprehensive intelligent network of objects that have the capacity to regulate automatically, share information, data, and resources, react and act in the face of situations and Environmental Change [3]. The Internet of Things is growing and continuing to be the latest concept most talked about in the world of IT.

In recent years, a large number of papers have proposed the design and implementation of the IoT gateways to smart home with Wired, wireless, and integrated both wired and wireless. With a wired home automation system, several researchers proposed systems with remote systems to control the temperature of water through transmission control protocols and Internet (TCP/IP) protocols with lower hardware costs. In the end, selected Internet Of Thngs system (IoT) is a system that not only able to reduce maintenance costs but also ordinary hardware/hardware with embedded WiFi module to communicate with the server provided by the Development and increase efficiency [4].

\section{Wemos DI RI}

Wemos D1 is a microcontroller compatible/similar to Ardunio Uno only just Wemos D1 based module ESP8266-12, which also can be enabled as a WiFi module. Wemos D1 has 11 digital input/ouput pins, 1 analog input pin, using microUSB as its serialize communication. The physical shape can be seen in Figure 1.

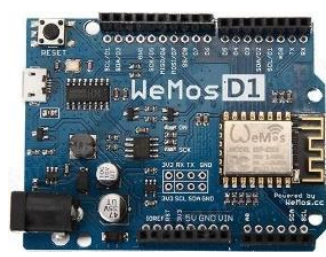

Figure 1.Wemos D1 [5]

\section{The sensors YHDC SCT 013-000}

The SCT-013-000 sensor is a sensor that serves to measure alternating current (AC). In the current sensor there is a CT, which is able to read the flow of AIR flows. SCT 013-000 Sensors are able to read current values up to $100 \mathrm{~A}$. With a dielectric of $1 \mathrm{kV}$. The physical form of the current sensor can be seen in Figure 2.

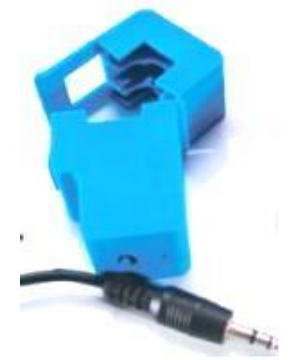

Figure 2.Sensor SCT 013-000 [6]

Temperature Sensor DS18B20 with water resistance (waterproof). Suitable for measuring temperature in difficult, or wet places. Since the data output of this product is digital data, DS18B20 provides 9 to 12-bit. DS18B20 by datasheet This sensor can read up to $125^{\circ} \mathrm{c}$, but it is recommended for use not exceeding than $100{ }^{\circ} \mathrm{c}$. The physical form of the temperature sensor can be seen in figure 3 .

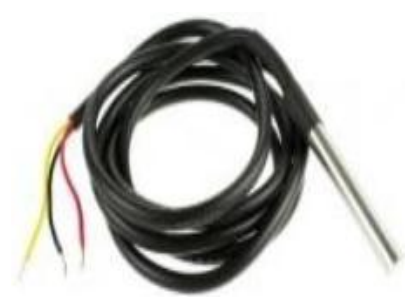

Figure 3.ThemperatureSensor DS18B20 [6]

\section{E. Analog to Digital Converter}

ADS1115 is an ADC (Analog to Digital Converter) with 16-bit precision level. About 860 samples/second through the I2C interface to communicate with the microcontroller. ADS1115 has the ability to measure 4 analog inputs at once (A0 - A3) shown in Figure 4.

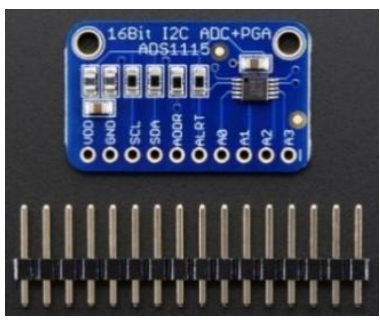

Figure 4. ADS1115 [7]

\section{F. Blynk app}

Blynk is a platform with iOS and Andorid applications to control Arduino, Raspberry $\mathrm{Pi}$ and the like through the Internet. It's a digital dashboard that can create graphical interfaces for projects with just drag and drop widgets. Blynk is very easy and simple, making the tools ready to connect to the Internet Of Things. Examples of BLYNK applications can be seen in Figure5.

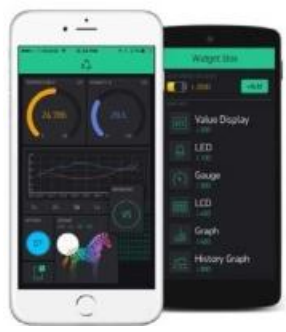

Figure 5.The Applicator Blynk [7]

\section{RESEARCH METHODS}

The approach in this study is a quantitative approach, as the research is presented in the form of numbers. This is in 
accordance with the opinion that suggests quantitative research is a much-demanded approach using numbers, ranging from data collection, interpretation of the data and appearance of results [9].

The flowchart of this research draft is found in Figure 5. Research will be conducted with the study of literature, using the theories that have been obtained the research will be continued to the planning and design procedures that the results will be compared and analyzed.

System design consists of two initial parts, namely hardware design and software architecture. The hardware design consists of a prototype transformer as well as a given load and the electric part is more detail in the show in figure6.

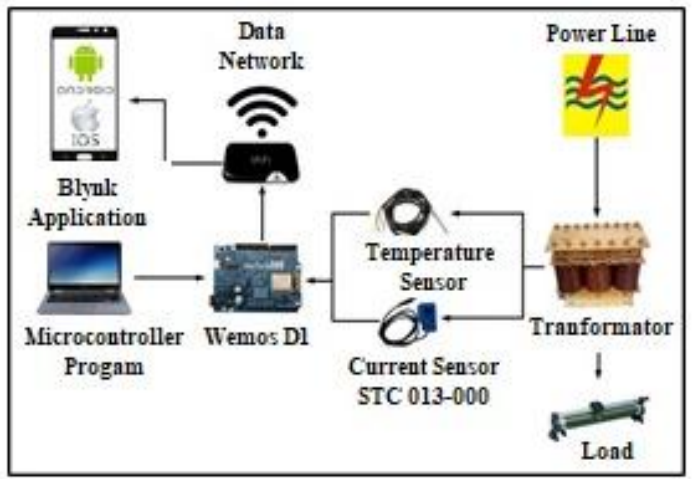

Figure 6. Relationships between electrical components

PC/Laptop is used for the initial program on the microcontroller to be used. Wemos D1 as an intermediary data acquisition device both computer and smartphone and sensors, with the intention of reading the value of inputs on digital or analog. Then the current sensor will be paired on the primary and secondary parts of the transformer, while the temperature sensor will be paired on the body transformer. It takes Mifi (Wifi Modem) as a liaison between users and microcontrollers.

Next on the software block consists of laptops, Internet connection, applications on the smartphone. In this research authors use the Blynk app found on the Google Play Store as an IoT service. From the laptop The program will be uploaded through the Arduino IDE to Wemos D1, then program on the Blynk application that will get the address Unique to synchronize with microcontroller. Where the design refers to the flowchart shown in Figure 7.

Based on that flowchart, the software work algorithm to be used is at the time when the software was first activated it would initialize the program that is related to the internal process of Wemos D1 R1.

The overview of the course program is reading the current and temperature values of the transformer prototype. Then setting the application Blynk and matching the address that has been given both the microcontroller and the application, so that both can exchange data and communicate. The result of sensor readings is displayed in the Blynk app.

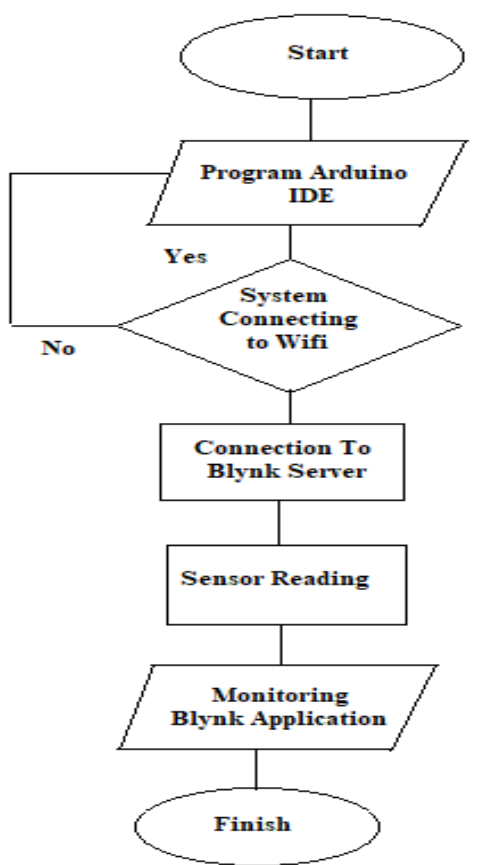

Figure 7. Software Design Flowcharts

\section{RESULTS AND DISCUSSION}

The results of prototype monitoring tools for currents and temperatures based on internet of things (IoT) are made of acrylic with a size of $14 \mathrm{~cm} \times 9 \mathrm{~cm} \times 4 . \mathrm{cm}$. On the outside, there are monitoring devices; there are R, S, T, SCT 013-000 temperature sensor and DS18B20 temperature sensor. On the inside, there are microcontroller Wemos D1, (Analog to Digital Converter) ADS1115, along with the circuit inside.

\section{A. Testing the current sensor SCT 013-000}

The sensor calibration process is carried out to get a more precise reading of the current value per unit percentage of current read and also know the level of accuracy on the SCT sensor 013-000. Sensor calibration is done by taking one sample from the SCT 013-000 sensor then comparing it to the reading of the Digital Clamp Meter or amperes pliers. Tests carried out under no load or zero loads. Then observe the change in output current value.

The comparison between SCT 013-000 sensor and Digital Clamp Meter can be seen in Table 1.

Table 1. Results of testing SCT 013-000 current sensor and Digital Clamp Meter

\begin{tabular}{lll}
\hline No. & Digital Clamp Meter & SCT 013-000 \\
\hline \hline 1 & $0,03 \mathrm{~A}$ & $0,03 \mathrm{~A}$ \\
\hline 2 & $0,02 \mathrm{~A}$ & $0,03 \mathrm{~A}$ \\
\hline 3 & $0,00 \mathrm{~A}$ & $0,03 \mathrm{~A}$ \\
\hline 4 & $0,01 \mathrm{~A}$ & $0,04 \mathrm{~A}$ \\
\hline 5 & $0,03 \mathrm{~A}$ & $0,03 \mathrm{~A}$ \\
\hline
\end{tabular}

\section{B. Testing the DS18B20 temperature sensor}

In this research data collection will be carried out by connecting the DS18B20 temperature sensor to the Wemos 
D1 microcontroller, then giving it a program and placing it on the transformer body.

The results of the DS18B20 temperature sensor testing accuracy at room temperature can be seen in Table 2 .

Table 2. Results of Testing the DS18B20 temperature sensor and Digital Clamp Meter

\begin{tabular}{lll}
\hline No. & Digital Clamp Meter & DS18B20 \\
\hline 1 & $30{ }^{\circ} \mathrm{C}$ & $30{ }^{\circ} \mathrm{C}$ \\
\hline 2 & $30{ }^{\circ} \mathrm{C}$ & $30{ }^{\circ} \mathrm{C}$ \\
\hline 3 & $29{ }^{\circ} \mathrm{C}$ & $30{ }^{\circ} \mathrm{C}$ \\
\hline 4 & $29{ }^{\circ} \mathrm{C}$ & $30{ }^{\circ} \mathrm{C}$ \\
\hline 5 & $30{ }^{\circ} \mathrm{C}$ & $30{ }^{\circ} \mathrm{C}$ \\
\hline
\end{tabular}

\section{Testing the Blynk}

Monitoring can be done on smartphones using the Blynk, which is available on Google Playstore and Appstore. Giving it the program to the microcontroller and its address, then connect it to the smartphone that is used. Distance or range testing is performed to find out how far the range of the ESP8266 WiFi module can transmit data.The test results can be seen in table 3, to find out how far the distance and influence with the sensor reading data can be sent or not. Testing is done in an open place without a wall barrier with the same Wifi connection.

Table 3. Testing the connection distance of the ESP 8266 module

$\begin{array}{ll}\text { No. } & \text { Distance (m) } \\ 1 & 5 \\ 2 & 10 \\ 3 & 20 \\ 4 & 30 \\ 5 & 40 \\ 6 & 50 \\ 7 & 60 \\ 8 & 70\end{array}$

Information

Data can be received on HP

Data can be received on HP

Data can be received on HP

Data can be received on HP

Data can be received on HP

Data can be received on HP

Unstable data

Unstable data

\section{Overall testing and analysis tools}

Of all the system block tests that have been carried out, and the entire tool have been tested, the performances of the tools have been running well. After that, analyze the data from measurements that have been taken. This test can be seen in Figure 8.

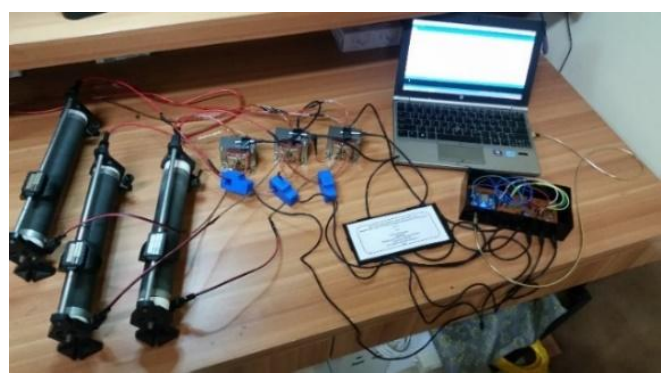

Figure 8. Testing of current and temperature monitoring system tools on an Internet of Things (IoT) -based distribution transformer.
In testing the tools, which includes reading the current and temperature in the three-phase transformer system that has been loaded with a rheostat then recorded each value that generated. Current and temperature parameters will be displayed on the Blynk as monitoring. The test results for the current value can be seen in Table 4.

Table 4. Results of current testing

\begin{tabular}{llllllll}
\hline $\begin{array}{l}\text { Load } \\
(\Omega)\end{array}$ & $\begin{array}{l}\text { Voltage } \\
(\mathrm{Vac})\end{array}$ & \multicolumn{2}{l}{$\begin{array}{l}\text { Prototype } \\
(\mathrm{A})\end{array}$} & & \multicolumn{4}{c}{$\begin{array}{l}\text { Digital } \\
\text { Meter }(\mathrm{A})\end{array}$} \\
\cline { 3 - 8 } & & $\mathrm{R}$ & $\mathrm{S}$ & $\mathrm{T}$ & $\mathrm{R}$ & $\mathrm{S}$ & $\mathrm{T}$ \\
\hline $11 \Omega$ & $18 \mathrm{~V}$ & 1.13 & 1.10 & 1.12 & 1.12 & 1.17 & 1.12 \\
\hline $10.5 \Omega$ & $18 \mathrm{~V}$ & 1.22 & 1.16 & 1.18 & 1.21 & 1.16 & 1.18 \\
\hline $10 \Omega$ & $18 \mathrm{~V}$ & 1.28 & 1.18 & 1.20 & 1.29 & 1.20 & 1.24 \\
\hline $9.5 \Omega$ & $18 \mathrm{~V}$ & 1.30 & 1.31 & 1.34 & 1.32 & 1.30 & 1.29 \\
\hline $9 \Omega$ & $18 \mathrm{~V}$ & 1.36 & 1.33 & 1.36 & 1.35 & 1.33 & 1.30 \\
\hline $8.5 \Omega$ & $18 \mathrm{~V}$ & 1.41 & 1.37 & 1.60 & 1.46 & 1.45 & 1.60 \\
\hline $8 \Omega$ & $18 \mathrm{~V}$ & 1.51 & 1.57 & 1.62 & 1.51 & 1.57 & 1.65 \\
\hline $7.5 \Omega$ & $18 \mathrm{~V}$ & 1.56 & 1.60 & 1.63 & 1.57 & 1.62 & 1.61 \\
\hline $7 \Omega$ & $18 \mathrm{~V}$ & 1.67 & 1.68 & 1.64 & 1.67 & 1.65 & 1.60 \\
\hline $6.5 \Omega$ & $18 \mathrm{~V}$ & 1.70 & 1.73 & 1.71 & 1.70 & 1.71 & 1.74 \\
\hline $6 \Omega$ & $18 \mathrm{~V}$ & 2.07 & 1.84 & 2.06 & 2.12 & 1.82 & 2.05 \\
\hline
\end{tabular}

From the measurement results in Table 4. that the current sensor is working properly. Using the amperage forceps on the installed load can prove this. For example, at a load of $6.5 \Omega$ in phase R, the current sensor SCT-013-000 measured current is 1.70 Amperes while the measurement results on the amperes pliers are 1.70 amperes. The measurement results indicate that the prototype tool can already be used as a current monitoring tool on the transformer. The error in the measurement of the current sensor SCT-013-000 compared to the amperes pliers can be calculated with the following formula: [Iegible value-actual value)]

$\%$ Error $=$ legible value $\times 100 \%$

From the above calculation, the average error in each $\mathrm{R}$ phase $=1.09 \%, \mathrm{~S}$ phase $=1.80 \%$, and $\mathrm{T}$ phase $=1.74 \%$, for the measurement of SCT-013-000 current sensor against the amperage pliers.

As for the results of temperature testing can be seen in table 5 .

Table 5. Results of Temperature Monitoring system

\begin{tabular}{lllllll}
\hline Load $(\Omega)$ & $\begin{array}{l}\text { Prototype } \\
\left({ }^{\circ} \mathrm{C}\right)\end{array}$ & \multicolumn{5}{c}{$\begin{array}{l}\text { Digital } \\
\left({ }^{\circ} \mathrm{C}\right)\end{array}$} \\
\cline { 2 - 7 } & $\mathrm{R}$ & $\mathrm{S}$ & $\mathrm{T}$ & $\mathrm{R}$ & $\mathrm{S}$ & $\mathrm{T}$ \\
\hline $11 \Omega$ & 35 & 35 & 34 & 39 & 40 & 39 \\
\hline $10.5 \Omega$ & 37 & 37 & 36 & 37 & 38 & 39 \\
\hline $10 \Omega$ & 37 & 36 & 35 & 37 & 38 & 39 \\
\hline $9.5 \Omega$ & 37 & 38 & 36 & 40 & 41 & 39 \\
\hline $9 \Omega$ & 37 & 37 & 36 & 40 & 40 & 39 \\
\hline $8.5 \Omega$ & 35 & 35 & 36 & 39 & 39 & 40 \\
\hline $8 \Omega$ & 34 & 34 & 35 & 35 & 37 & 40 \\
\hline $7.5 \Omega$ & 33 & 32 & 34 & 35 & 35 & 38 \\
\hline $7 \Omega$ & 33 & 30 & 33 & 33 & 31 & 35 \\
\hline $6.5 \Omega$ & 34 & 28 & 33 & 27 & 27 & 32 \\
\hline $6 \Omega$ & 35 & 34 & 36 & 37 & 32 & 35 \\
\hline
\end{tabular}


From the test results in Table 5, the accuracy of the temperature sensor is almost close to the measuring tools or amperes pliers used. For example at a load of $6 \Omega$ in the R phase DS18B20 temperature sensor, the temperature measured on the prototype tool was $35^{\circ} \mathrm{C}$, while the ampere pliers was $37^{\circ} \mathrm{C}$. Which means the error in the measurement on the temperature sensor DS18B20 compared to the amperage pliers can be calculated with the following formula: [Clegiblevalue-actual walue]]

$\%$ Error $=$ legible value $\times 100 \%$

From the above calculation, we get the average error in each $\mathrm{R}$ phase $=3.1 \%, \mathrm{~S}$ phase $=5.8 \%$, and $\mathrm{T}$ phase $=8.0 \%$, measurement of DS18B20 temperature sensor against amperage pliers.

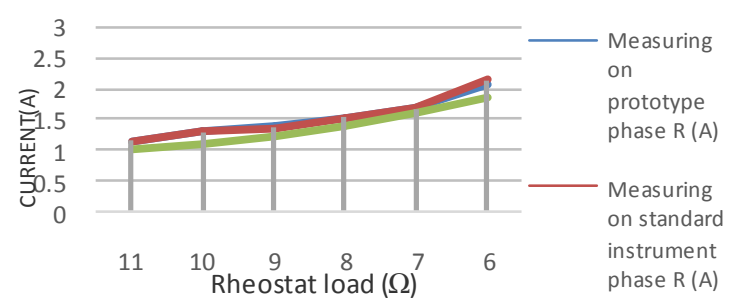

Figure 9. Graph of Measurement Results Phase R

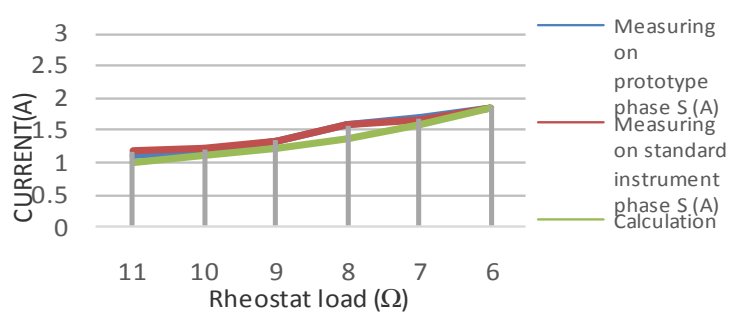

Figure 10. Graph of Measurement Results Phase S

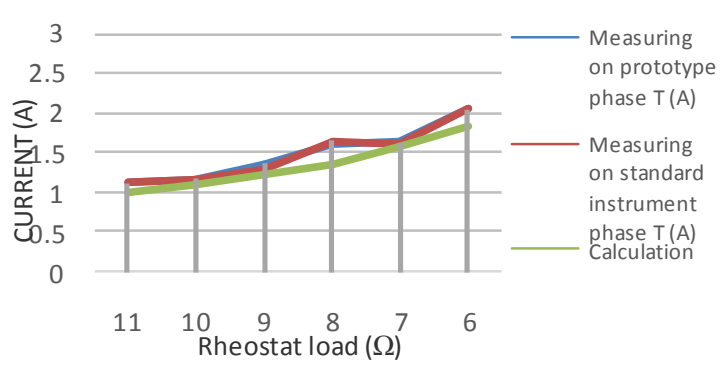

Figure 11. Graph of Measurement Results Phase T

\section{CONCLUSION}

The average of error measurements produced by an Internet-based monitoring system of things (IoT) against a standard measuring instruments, with the test flow per phase is $\mathrm{R}=1.0 \%, \mathrm{~S}=1.8 \%, \mathrm{~T}=1.7 \%$ and accuracy of temperature error per phase is $\mathrm{R}=3.1 \%, \mathrm{~S}=5.8 \%, \mathrm{~T}=8.0 \%$. Response sending sensor values to the interface contained in the application is very dependent on the speed of the Internet connection available, with a maximum test distance of $50 \mathrm{~m}$.

For further research, it would be nice to add a voltage sensor and voltage indicator along with the power indicator so that the result data will be more complete as well as the next action taken, if the transformer is interrupted.

\section{REFERENCES}

[1] Winardi, Bambang, "Monitoring Planning Power Transformer Temperature 150/20 KV-based Arduino Mega 2560,",Department of Electrical Engineering Faculty of Engineering Diponegoro University, 2017.

[2] Rahardy Bryan, and et al.."Monitoring The condition of power transformer Online based Data analysis temperature, voltage, and current on the distribution Transformer," Department of Electrical Engineering Faculty of Technology of the ten-November Institute of Technology (ITS), 2012.

[3] [3]. Nicholas Liew Long Guang, ThillainathanLogenthiran, dan Khalid Abidi, "Application of Internet of Things (IoT) for home energy management," IEEE PES Asia-Pasific Power and Energy Engineering Conference (APPEEC), 2017.

[4] .https://www.instructables.com)

[5] https://www.adafruit.com)

[6] https://www.Blynk.cc)

[7] Suprianto, Bambang and Lucky A, "Control System Of Current Flow 3-Phase Unbalanced Based On Arduino Uno, International Journal of Engineering and Applied Sciences (IJEAS) ISSN: 2394-3661, Volume-4, Issue-9, September 2017.

[8] Suprianto, Bambang. Wireless Sensor Network Based Atmega16 Microcontroller as Temperature and Current Monitoring System on Distribution Network Transformator". IOP Conference Series: Materials Science and Engineering, Vol 288, Conference 1, 2018.

[9] Mohan, Ned, "Electric Power System," Amazon.com, 2012. 